\title{
Teaching Intraverbal Storytelling to Children with Autism and Other Cases of Language Delays
}

\author{
Daniel Carvalho de Matos ${ }^{1}$, Pollianna Galvão Soares de Matos'1, \\ Rosana Mendes Éleres de Figueiredo² \\ ${ }^{1}$ Department of Psychology, Ceuma University, São Luís, Brazil \\ ${ }^{2}$ Department of Psychology, Federal University of Maranhão, São Luís, Brazil \\ Email:dcmatos23@hotmail.com
}

How to cite this paper: de Matos, D. C., de Matos, P. G. S., \& de Figueiredo, R. M. É. (2017). Teaching Intraverbal Storytelling to Children with Autism and Other Cases of Language Delays. Psychology, 8, 798-814. https://doi.org/10.4236/psych.2017.86051

Received: February 21, 2017

Accepted: April 25, 2017

Published: April 30, 2017

Copyright $\odot 2017$ by authors and Scientific Research Publishing Inc. This work is licensed under the Creative Commons Attribution International License (CC BY 4.0).

http://creativecommons.org/licenses/by/4.0/

\begin{abstract}
In Brazil, it is estimated that there are approximately 2 million youngsters and children diagnosed with autism and other cases of learning disabilities, a factor that has led to an increase on the demand for treatment aimed at the development of basic and academic skills, such as reading, writing, fluency in interpreting texts, recalling and retelling a story dictated by a teacher. The purpose of the present investigation was to assess the efficacy of a procedure to teach intraverbal storytelling to four Brazilian children (two autistic and two with language delays). Three stories were taught to each participant and each story comprised four segments represented by pictures and written scripts. The participants had opportunities to read the scripts with help from the experimenter if necessary and, after an interval, they had to retell the stories. During training, echoic and visual prompts were administered as corrections whenever a given child was unable to retell a given segment appropriately. Correct responses free from prompts resulted in praise and a token. After gathering a given number of tokens, the participants could exchange them for a preferred item like a toy or a favorite activity. As result, the participants were able to retell the stories correctly when compared to baseline levels. Only one was unable to retell all the segments of the third story, probably because she did not have more time to be exposed to the programming contingencies due to the period of recess from school. The results provide education professionals with specific directions for advocacy and service delivery that aim to enhance school outcomes for students with ASD.
\end{abstract}

\section{Keywords}

Intraverbal Storytelling, Autism Spectrum Disorder, Language Delay, School 


\section{Introduction}

The basic education policies of Brazil indicate that the aim of the schools is to develop reading, writing and calculation skills, in their different stages and levels of schooling, the basic preparation for higher education, work and citizenship, starting from an ethical formation, the development of intellectual autonomy and critical thinking and the understanding of the scientific-technological foundations and the productive processes. Specifically, Brazilian special education is based on the National Policy on Special Education in the Perspective of Inclusive Education, promulgated in 2008 by the Special Education Secretariat of the Ministry of Education (Brazil, 2008). This policy protects, as a central principle, the defense that every learner has the right to learn and participate in a school environment without any kind of discrimination, guiding education systems to provide strategies to meet special educational needs, expanding learning and development of students with intellectual disabilities, such as autism spectrum disorder (ASD) (Fleith, 2011; Galvão \& Beckman, 2016).

In Brazil and in the world, the increase in the number of students diagnosed with autism spectrum disorder has raised the demand from parents and institutions for methods of evaluation and intervention based on scientific evidence for the implementation of practices of school inclusion, such as curricular adaptation, hiring specialized professionals for educational intervention in the school and complementary activities that enhance and amplify the basic academic skills already acquired by the student (Elsabbagh et al., 2012; Galvão \& Beckman, 2016; Garbacz \& McIntyre, 2016; Goitein \& Cia, 2011; Nunes \& Santos, 2015; Stichter, Riley-Tillman \& Jimerson, 2016). However, education professionals are not yet adequately prepared for the challenge of offering specific pedagogical interventions for the development of academic skills in students with ASD. Although brazilian federal law advocates the inclusion of specialized educators in regular schools (Brazil, 2012), they are often identified as specialized education professionals for disabilities other than autism (for example, specific learning difficulties, Down syndrome or other learning and development disabilities).

Mitjáns-Martinez (2009) points out that, historically, there is a strong tendency to associate the concept of school inclusion with the inclusion of students with special educational needs in a context of students with supposed standard development. Besides being a misconception, it places the need for special education as particularized exclusively in the subject. Thus, the need for appropriate evidence-based assessments and interventions for students with ASD, that may be applicable in the context of school, is critical.

Considering these basic assumptions of education, as well as seeking to understand and discuss the process of development of children diagnosed with autistic and other cases of learning disabilities, this research aimed to assess the efficacy of a procedure to teach intraverbal storytelling to four brazilian children (two autistic and two with language delays) and that it is a required skill of the school activities. Many children with autism show deficit in developmental areas such as language and communication. They may present difficulties with both 
expressive and receptive language. In Brazil, national researchers have undertaken efforts to understand the phenomenon of autism and propose appropriate forms of intervention that favor the development of skills necessary for the schooling process. The reader may refer to publications by Gomes, Silveira and Rates (2016) and Matos (2016) as examples.

Psychological science, with regard to its commitment to human development, bases its proposals for intervention in the light of the theoretical foundations that guide them. This study adopted the Behavior Analysis as a theoretical subsidy for the methodological organization of the procedures. Behavior Analysis is one of the theories of Psychology that supports a theoretical and methodological proposal recognized as relevant for the implementation of the pedagogical policy of the school focused on inclusion in Brazil (Galvão \& Beckman, 2016).

\section{The Applied Behavior Analysis as a Possibility of Intervention to the Student with ASD}

Skinner (1957) established basic principles derived from operant conditioning like reinforcement, which may be applied to human issues to produce relevant behavior change. That is the case of the work on deficits demonstrated by individuals with autism. Some of the deficits are related to language that is viewed by behavior analysts as a kind of operant behavior and the same laws that govern other operants applies to language as well. It was defined by the author as verbal behavior. He did not work with autistic individuals, but his contributions to human science served as the basis for many applied behavior analysts who develop procedures to produce important behavior change in individuals with ASD.

The verbal behavior is shaped and maintained by mediated consequences. According to Skinner (1957), a verbal episode comprises interactions between a speaker and a listener. The speaker emits a verbal response and the listener delivers a reinforcing consequence, which strengthen the verbal response. There are several functions of language or verbal operants and they comprise a verbal response and environmental variables responsible for their maintenance.

One case implies that, when a motivating operation, such as the willingness to eat a favorite food, is present, a speaker approaches a listener and he/she says "can you give me a cookie, please?". The listener by his/her turn delivers a cookie to the speaker. The verbal behavior is reinforced by a specific consequence described by the speaker. Another kind of verbal operant may involve a situation when an adult presents, for example, a picture of a cookie and asks a child "what is this?". The child then says "cookie" and the adult says "that is correct!". The verbal operant by the child was named "tact" by Skinner (1957) and the consequence mediated by the adult represents a generalized reinforcer.

The first two cases of verbal operants presented in this manuscript may occur under the control of a non-verbal antecedent stimulus, although not necessarily, considering that, for the mand, the presence of a visual stimulus such as the cookie itself is not needed for the child to ask for it. The verbal response may be 
emitted when the reinforcer itself is out of sight and the response is supposedly controlled by the motivating operation. However, it is common that some children with autism are not able to respond when a visual stimulus is not present. There are verbal operants, which are emitted under the presence of verbal antecedent stimuli. In one case, for example, an adult presents a verbal antecedent stimulus like "say cookie" and the child repeats "cookie". The adult then says "that is right!", the generalized reinforcer responsible for maintaining the response. There is a point-to-point correspondence between the verbal antecedent stimulus and the response. This verbal operant is called by Skinner (1957) "echoic" and represents the prerequisite for the establishment of other verbal operants, like the mand and the tact, with a vocal topography. Another case of verbal operant controlled by a verbal antecedent stimulus is called "intraverbal" and poses a harder challenge for many children with autism and other cases of developmental disabilities due to the lack of point-to-point correspondence between the verbal antecedent stimulus and the response. As an example, consider the case of an adult who approaches a child and asks "what do you eat?". The child on his/her turn, says "cookie" and the adult says "that is correct!".

This generalized reinforcer maintains the verbal response that is considered correct due to arbitrarily established criteria by the verbal community. This manuscript emphasizes this particular verbal operant, considering the cases of many children that, although present a repertoire with hundreds of words and phrases emitted as mands and tacts (expressive language) and also a good performance on tasks that require receptive responses (listener behavior), lack the intraverbal repertoire. Several studies on Applied Behavior Analysis have focused on the establishment of two kinds of intraverbal repertoire: answering questions, like studies done by Finkel and Williams (2001); Ingvarsson, Tiger, Hanley, and Stephenson (2007); Sundberg and Sundberg (1990); and naming stimuli that are members of several categories, like studies by Braam and Poling (1983); Goldsmith, LeBlanc and Sautter (2007); Grannan and Rehfeldt (2012); Miguel, Petursdottir and Carr (2005); Partington and Bailey (1993); Petursdottir, Carr, Lechago and Almason (2008); Sautter, Leblanc, Jay, Goldsmith and Carr (2011).

Some studies comprised methodologies of teaching that focused on changing the stimulus control by manipulating echoic prompts and tact prompts. As an example, consider the case of the adult who presents the question "what do you eat?". If the child can't answer this question appropriately, but has a good repertoire of tact and echoic behavior, the adult can manipulate one of them as a prompt. One possibility is when the adult, immediately after the question, presents an echoic model by saying "cookie" or a picture portraying the cookie as an opportunity for a tact response. As the child responds under the control of the prompt correctly during several trials, the adult may begin to gradually fade out the prompt by delaying its presentation. This is done in order to make a change on stimulus control possible. That means that, with time, the controlling variable shifts from the prompt to the verbal antecedent stimulus solely, the 
question "what do you eat?", which sets the occasion for the intraverbal response, as suggested by several authors: Braam and Poling (1983), Coon and Miguel (2012), Finkel and Williams (2001), Golsmith et al. (2007), Humphreys et al. (2013), Ingvarsson and Hollobaugh (2011), Ingvarsson (2011), Kodak, Fuchtman and Paden (2012), Miguel et al. (2005), Petursdottir et al. (2008); Petursdottir, Ólafsdóttir, Aradóttir (2008), Polick, Carr and Hanney (2012), Sundberg and Sundberg (1990), Valentino, Shillingsburg and Call (2012), Vedora, Meunier and Mackay (2009).

In some of the mentioned studies, a textual prompt was used besides a tact or echoic prompt like Braam and Poling (1983), Emmick, Cihon and Eschleman (2010), Finkel and Williams (2001), Ingvarsson (2011), Vedora and Conant (2015), Vedora, Meunier and Mackay (2009). According to Skinner (1957), the textual behavior occurs when, for example, an adult presents a flashcard with a printed word "cookie" on it and a child says "cookie" out loud. The adult then socially reinforces the correct response. It is also important to point out that there were studies by Grannan and Rehfeldt (2012), Miguel et al. (2005), Partington and Bailey (1993), Petursdottir, Carr, Lechago and Amalson (2008) that investigated the effects of teaching other repertoire (tacting categories) over the emergence of intraverbals in typically developing children and also children diagnosed with autism. On these studies, the intraverbals were not directly taught and it was possible to notice the emergence effect to some extent in some participants.

Overall, all of the verbal operants plus several other non-verbal repertoires are important for human development in several social relevant environments, including family and school. Impairment on these repertoires draws the attention to the need of establishing special treatments to ameliorate the difficulties. The case of intraverbal frequently is a critical one. It is considered the most complex verbal operant to teach, according to Sundberg (2008). Problems with this repertoire may be due to the fact of a child being unable to respond appropriately even to simple verbal antecedents, such as "tell me your name". Besides there may be a problem like rote responding, considering that, even if a certain child learns how to answer correctly to the verbal stimulus mentioned, he/she may fail to generalize the response to variations of the verbal stimulus such as "who are you?" which sets the occasion for the same response. Impairments on generalization may also be verified when a child fails to vary the response under a verbal stimulus which sets the occasion for more than one kind of verbal response as correct. That is the case when an adult presents "name an animal" to a child. $\mathrm{He} /$ she may manage to give a correct response like "dog", but fail to vary the response when the adult says "name another animal".

Sundberg (2008) states that the reasons why the intraverbal behavior is harder to teach in comparison with other verbal operants are many and he listed some. He says that the verbal antecedent stimuli composed of words and sentences are constantly changing and typically consist of many parts. On the other hand, the antecedent stimuli that evoke other verbal operants tend to be constant as well as 
the responses. In the case of intraverbal, both the stimulus and the response are constantly changing. A discussion about a matter is comprised of hundreds or even thousands of intraverbal relations. And the author also states that the discussion on a certain matter may never occur the same way in other opportunities.

The intraverbal repertoire is essential for the child's development at school, including on academic activities. Complex intraverbals may be established with a focus on reading comprehension, for example. That is the case when a child has to read a story and then he/she has to retell it to an audience like a teacher and classmates. This case is way more complex than the other examples of intraverbals previously presented on this manuscript due to the fact that it comprises the relation between several verbal antecedent stimuli and responses composed of many combinations of words and phrases. The teaching of this ability demands that the child already be familiar with more simple intraverbal relations and other verbal operants, including tact, echoic and textual behavior.

Valentino, Conine, Delfs and Furlow (2015) conducted a recent study focused on teaching intraverbal storytelling to children with autism. The purpose was to assess the efficacy of a methodology to teach storytelling to three children with autism (age ranging from 4 to 8 years old). Each story was comprised of several segments and each segment consisted of a picture and a written script. All the stories were presented in books. Four stories with ten segments and six words on each segment were used for the first participant. Five stories with five segments and six words on each segment were used for the second participant. Five stories with eight segments and five words on each were used for the third participant. The dependent variable (VD) consisted of correct verbalizations of all the segments of each story. Responses that consisted of approximations (use of synonymous, change of words, articles omission) of the scripts were also considered when there was no change on the meaning. Besides the responses were also considered correct when they were emitted sequentially, but not necessarily consecutively. As an example, if a child retold the segment number four after segment one, this was registered as a correct response. To demonstrate the effects of the intervention over the VD, a multiple baseline design across stories was implemented.

The first condition of the research by Valentino et al. (2015) was a baseline 1) when the experimenter only asked the children to tell each story to ensure that they were not familiar with them. There were no programmed consequences for correct or incorrect responses. On a second condition 2) named "reading", the experimenter read each story while showing each picture and written script of each segment. When the experimenter was done, she/he asked each child to retell the story after $30 \mathrm{~s}$. During the treatment condition 3), the experimenter employed a backward chaining procedure combined with the manipulation of textual and visual prompts and differential reinforcement for correct responses. Each session comprised an assessment trial, a trial with prompts and a transfer trial. During an assessment trial, the contingency to respond was the same as the one applied during baseline, except by the fact that correct responses were fol- 
lowed by praise and access to preferred tangible items. If a given participant was unable to verbalize all the segments of the story being assessed, a trial with prompts was initiated. On this case, the experimenter presented a verbal antecedent such as "tell me the story of..." and opened the book that contained all the segments of the story. The first page was showed with the first segment, so the child could describe it. If the child was unable to describe the picture or read the script, the experimenter pointed to the words and provided the names orally, so the child could repeat them.

This procedure was done until the entire story had been presented. After this, a transfer trial was initiated. The purpose of this one consisted of shifting the control by the visual stimuli to the verbal antecedent "tell me the story of..." solely. Since this represented the backward chaining procedure, each targeted segment of the story was covered with a white sheet of paper. If the targeted segment was the last one, all the previous ones were first presented and the child had the opportunity to describe them with the help from the experimenter with echoic and textual prompts, if necessary. During the presentation of the targeted segment, the visual stimuli were covered, so the child had an opportunity to describe the segment without the need of prompts. During other sessions, after the child described the targeted segment correctly during two consecutive assessment trials, the criteria changed to include both the mastered last segment and the previous one and the visual stimuli from both segments would be covered during the transfer trials. The same criteria for inclusion of the other segments remained until the children were able to retell the entire story on two assessment trials and without the need of prompts.

As result, Valentino et al. (2015) pointed out that the procedures effectively established the intraverbal storytelling for all of the participants with autism. Plus, they stated that a generalization effect was observed since the correct responses were collected in different environments and under the presence of new instructors. Nevertheless, the authors also pointed out that changes on the procedures were needed for two participants because of a low frequency of correct responses and repetitive verbalizations. The changes included 1) the presentation of vocal prompts during transfer trials and assessment trials to stop the vocal stereotypies and redirect the children back to task; 2) use of a book similar to the one from the original stories but with all the pages blank (on this case, the children did not respond if the book was absent); 3) use of verbal rules about getting back to describing the story. This was used for one participant to interrupt the repetitive verbalizations.

The study by Valentino et al. (2015) focused on procedures of social and academic relevance and may represent a way of helping children with autism and other developmental disabilities to acquire complex intraverbals, which are necessary in several contexts, including school. Many children seem to have difficulty in developing necessary repertoires for reading comprehension. The impairments pose a challenge for educators and interventionists. The present study had some features similar to the ones described in the research by Valentino et 
al. (2015). Nevertheless, the backward chaining was not used and two of the four participants had been diagnosed with autism (the other two non-autistic children presented delay in language acquisition, especially intraverbals). Overall, the present study focused on answering the following research question: are the procedures to teach intraverbal storytelling effective for children with autism and other cases of language delays, when a backward chaining procedure is not administered?

\section{Method}

\section{Participants, Settings and Materials}

Four brazilian children participated in the research. Two of them (P1 and P2) were diagnosed with autism and the remaining (P3 and P4), although non-autistic, showed delays in language acquisition. All of them benefited from Applied Behavior Analysis (ABA) services at home, but the procedures from the current study were applied at the context of a clinic situated in a private university in Brazil. Each child was attended individually and the teaching area contained a table, chairs and materials necessary for the sessions, like flashcards portraying scenes and printed texts that could be manipulated to construct stories. The flashcards measured $6 \times 3 \mathrm{~cm}$, each story consisted of four segments and each segment represented a different flashcard and a printed text. Three stories, that were four segments in length, were used for all participants, the segments contained from three to nine words and the texts were written in Portuguese.

Before the beginning of data collection through the main procedures from this research, an assessment was conducted in order to establish important verbal behavior repertoire for each participant. According to the Verbal Behavior Milestones Assessment and Placement Program/VB-MAPP by Sundberg (2008), all of the children were performing beyond level 2 in some aspects and their repertoires comprised the abilities of making requests (mands) using phrases; they were able to identify hundreds of items and pictures as both speaker (tact) and listener (receptive language); they were able to demonstrate generalized matching to sample skills; they were able to manipulate toys appropriately and in a functional way; all of them were developing social abilities for a better interaction with the typically developing children at the same age; all of them showed both generalized motor imitation and vocal imitation (echoics); they were all able to identify many stimuli as both listener and speaker (intraverbal) by their functions, features and classes; their abilities to participate in group activities at school were also improving, even though some deficits were still a reality; they were developing better abilities to communicate with other people with proper grammar use, although three of them in particular still showed difficulties to use articles, prepositions and specially pronouns in sentences. All of them were able to read (textual behavior) several words and phrases. Regarding the duration of the study, all sessions were conducted two or three times per week until completion.

\section{Response Measurement}

The primary dependent variable was retelling the story segments correctly. All 
participants had to vocally retell all segments of a story after reading it with or without the experimenter's aid. Response approximations were also accepted if the meaning was preserved. The approximations included use of synonyms, omission of articles and word reversals. The mastery criterion for an entire story consisted of two blocks of trials with 100\% correct responses. Each trial represented one segment of a story, but after the mastery criterion was achieved for a given story, the same was still presented for maintenance purposes.

\section{Interobserver Agreement (IOA)}

One experimenter was responsible for conducting the assessments and interventions during the research and also collected data. However, another person also collected data during approximately $40 \%$ of the sessions in order to obtain the IOA. This was calculated by dividing the number of agreements by the number of agreements plus disagreements and multiplying by 100 to obtain a percentage. The mean IOA was $98 \%$ for all participants.

\section{Procedure}

Experimental design. To ensure that the development of the targeted intraverbal behaviors was a function of the applied intervention, a multiple baseline design across stories was used.

Baseline. During this condition, the verbal instruction "tell me the story about..." followed by the name of a given story was presented to each child, who had 30s to respond. No consequences were programmed for incorrect responses or no responses. If the child could retell any of the story segments, the experimenter praised him/her and asked to continue. However, no child was able to describe any of the segments.

Reading. During this condition, the experimenter first read the entire story one time while pointing to the words and the pictures portraying the segments. After reading, the experimenter allowed $30 \mathrm{~s}$ to pass and asked each child to retell the story just as in baseline. The consequences for correct, incorrect responses or no responses were the same as those administered during baseline.

Treatment. The experimenter first read the entire story one time while pointing to the words and the pictures portraying the segments like on the previous condition. After reading and allowing $30 \mathrm{~s}$ to pass, the experimenter asked each child to retell the story. They had from $3 \mathrm{~s}$ to $5 \mathrm{~s}$ to retell each segment in order. As the time passed and a given segment was not verbalized within the limit, or if an incorrect response was given, the experimenter presented the picture and text representing the segment as correction. The mastery criterion for each story was performing $100 \%$ correctly, and without the need for prompts, in two blocks of trials. When the criterion was met, training continued to ensure maintenance.

\section{Results}

Figures 1-4 shows the number of correct story segments during baseline, reading and treatment condition for P1, P2, P3 and P4, respectively.

As it can be seen in Figure 1, P1 did not retell any story segments during 


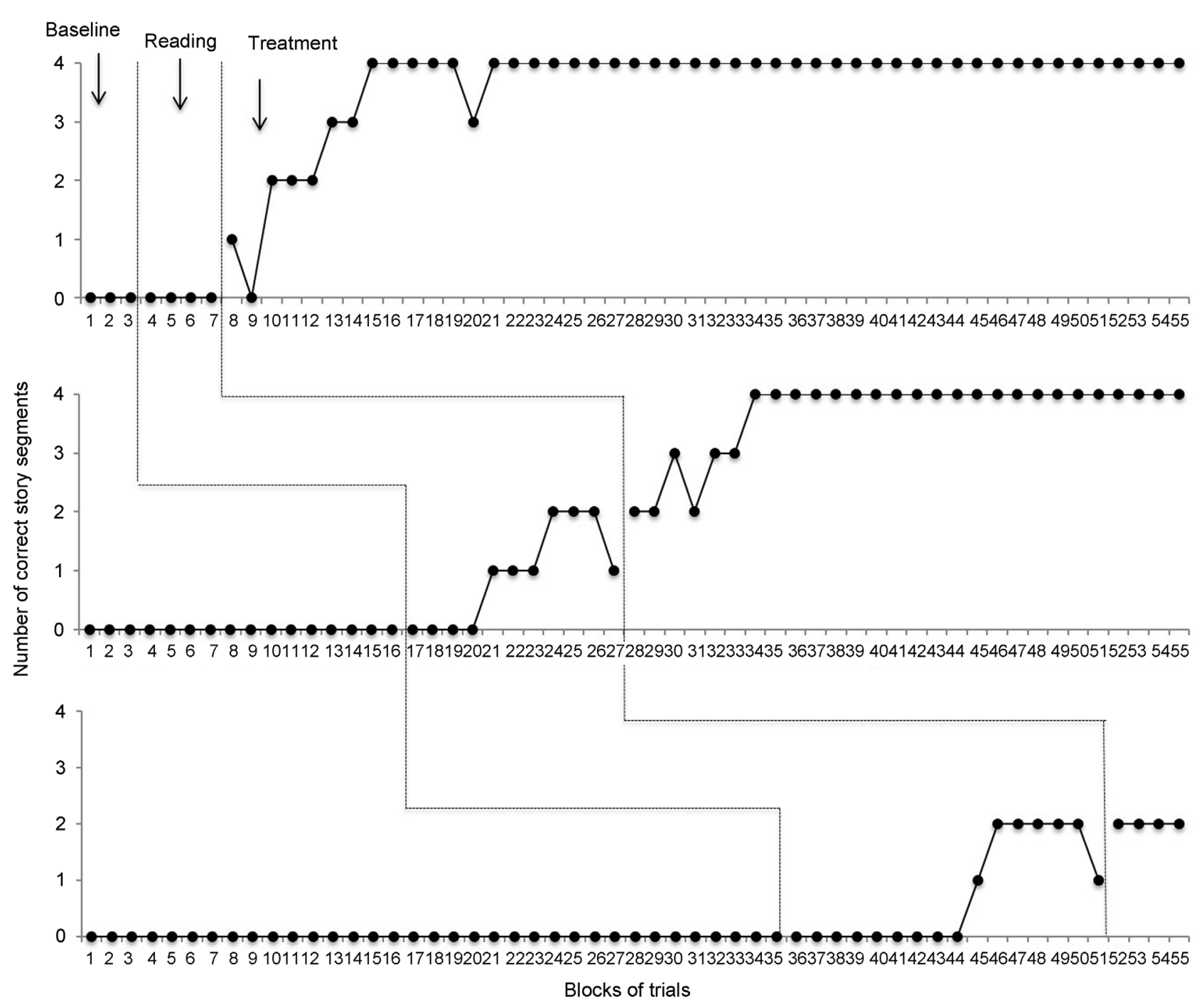

Figure 1. Number of correct story segments by P1 during baseline, reading and treatment condition. The upper, middle and lower graphs represent stories 1,2 and 3 , respectively.

baseline for the three stories. When the reading condition was implemented for the first story, no correct responses were emitted as well. During treatment, nine blocks of trials were needed to achieve criterion. During the following training, performance dropped to three correct responses in a block of trials once, but then performance was kept on $100 \%$ correct responses until the end of data collection. For the second story, treatment condition was also effective and criterion was met after eight blocks. During the third story, the condition was not finished because vacation time started and data collection was interrupted. It is interesting to note that P1 was able to retell some of the second and third story segments during several blocks of trials of the reading condition.

Figure 2 shows that P2 did not emit any correct responses during baseline. For the first story, no segment was retold during reading condition. Treatment condition shows that criterion was achieved after 11 blocks of trials. During the second and third story, the reading condition was not enough to establish a repertoire free from errors, although P2 was able to retell three story segments correctly 


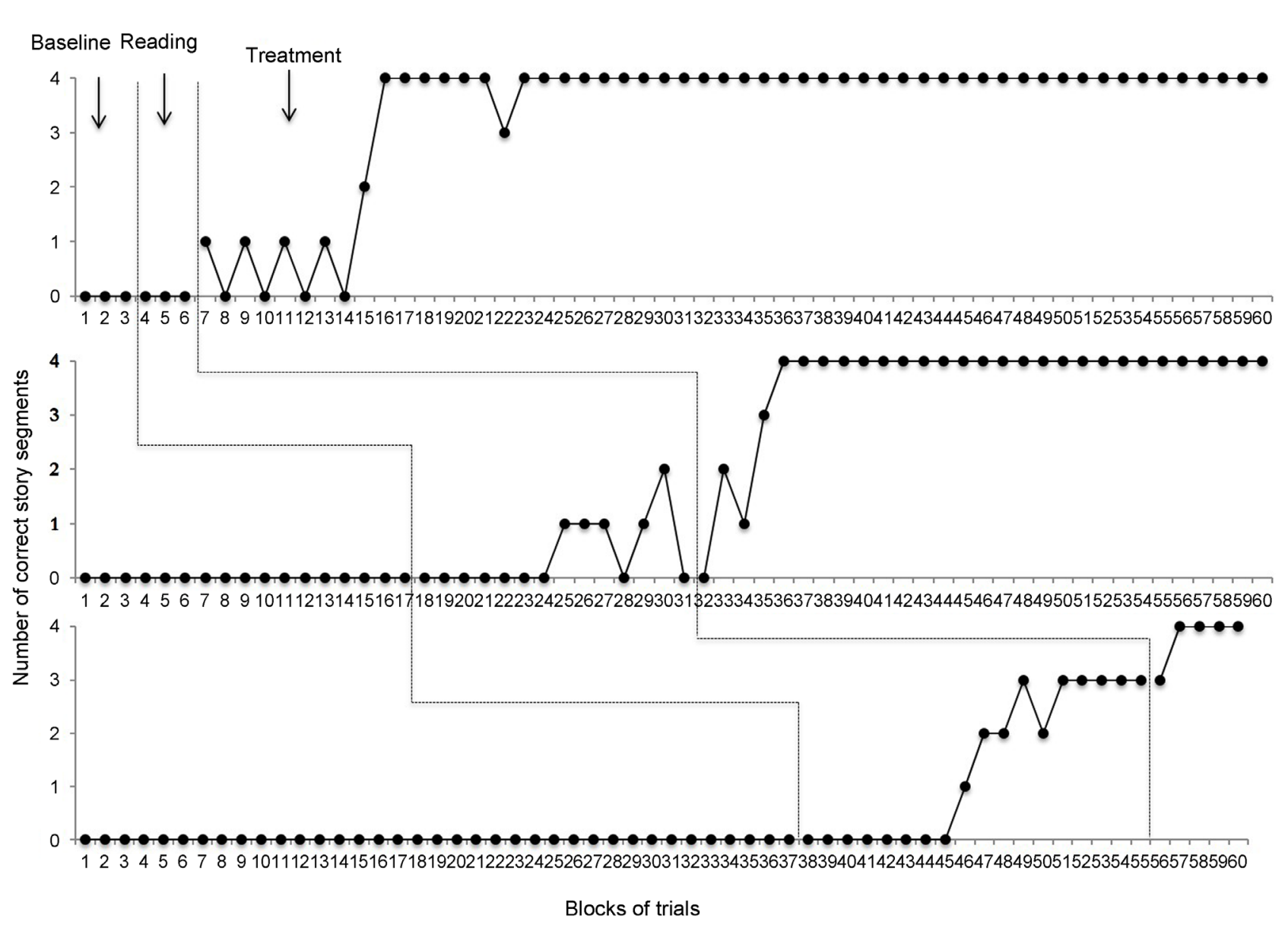

Figure 2. Number of correct story segments by P2 during baseline, reading and treatment condition. The upper, middle and lower graphs represent stories 1,2 and 3 , respectively.

in five consecutive blocks of trials (third story). The treatment condition was effective for both second and third stories with six and three blocks to meet criterion, respectively.

Figure 3 shows that P3 did not emit any correct responses during baseline. For the first story, the performance during the reading condition remained at three correct responses for three consecutive blocks of trials before implementation of the following condition. During treatment, six blocks were necessary to meet criterion and the performance remained at $100 \%$ accuracy during all the remaining blocks of trials. For the second and third story, the reading condition was also not sufficient to establish the repertoire, but the treatment condition was effective. The number of blocks of trials needed to achieve criterion was five and three for the second and third story, respectively.

Figure 4 shows that P4 did not emit any correct responses during baseline. For the first story, there were no correct responses during the reading condition and the treatment was effective in establishing the intraverbal storytelling. Seven blocks of trials were necessary to achieve criterion. During the second and third story, the reading condition was also not enough to establish the repertoire, although $\mathrm{P} 4$ was able to retell one segment of the third story twice. The treatment condition was effective and seven and five blocks were necessary to meet criterion 


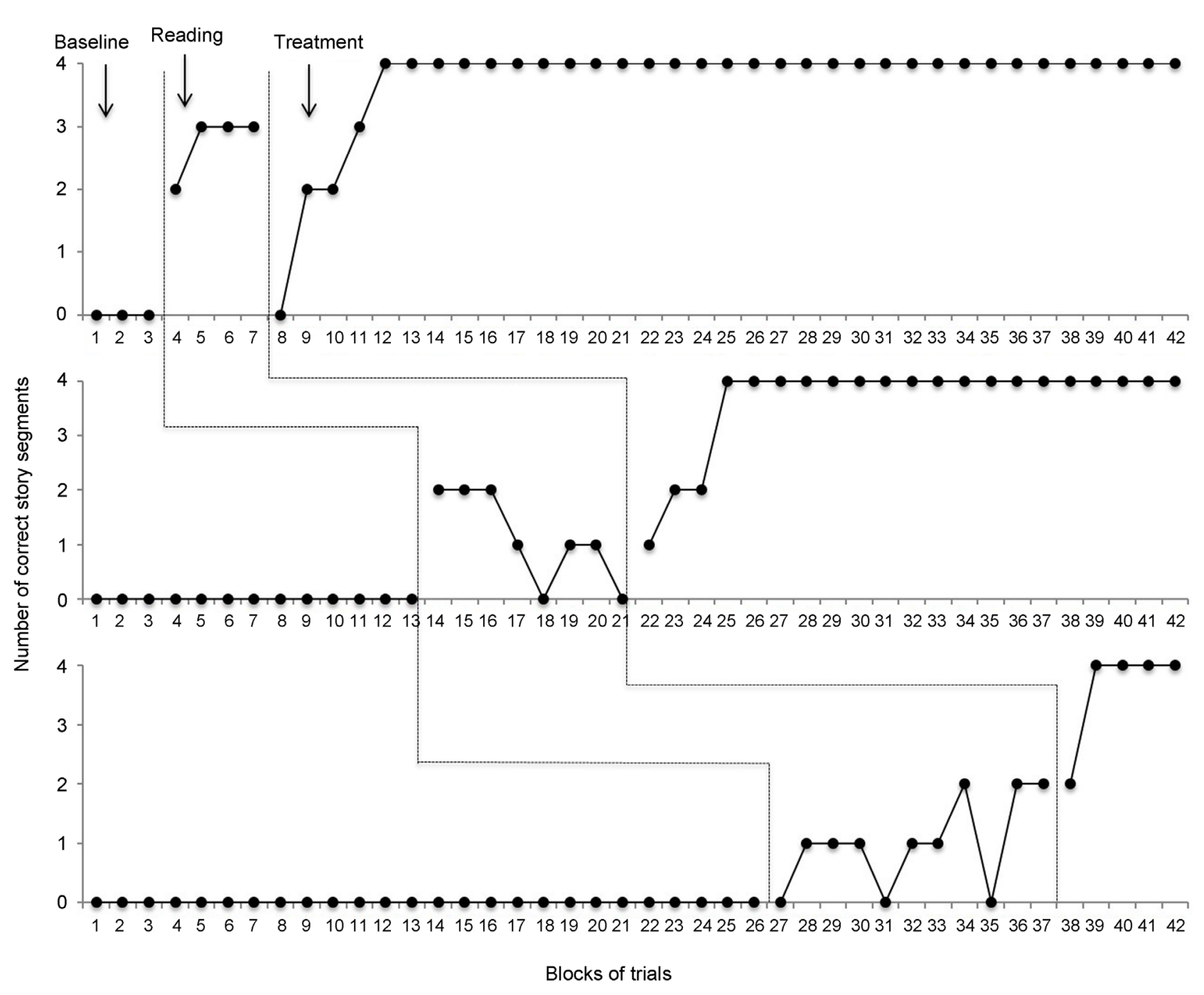

Figure 3. Number of correct story segments by P3 during baseline, reading and treatment condition. The upper, middle and lower graphs represent stories 1, 2 and 3, respectively.

for the second and third stories respectively.

\section{Discussion}

Literature has been corroborating data appointed in the classical study by Lovaas (1987), which indicates that behavioral treatment may produce lasting and significant benefits to children with autism, as documented in further studies by McEachin, Smith, and Lovaas (1993) and Sallows and Graupner (2005). The data from the current study suggest that the treatment condition was effective in establishing a correct complex intraverbal storytelling repertoire for all four participants. Two of them are autistic. However, all participants have difficulties with intraverbal behavior, specially the ones related to tasks of academic relevance such as reading comprehension and recalling and retelling a story dictated by a teacher or read by the student him/herself.

The backward chaining procedure was not used as in the Valentino et al. (2015) study and the participants were also encouraged to read all the story segments, 


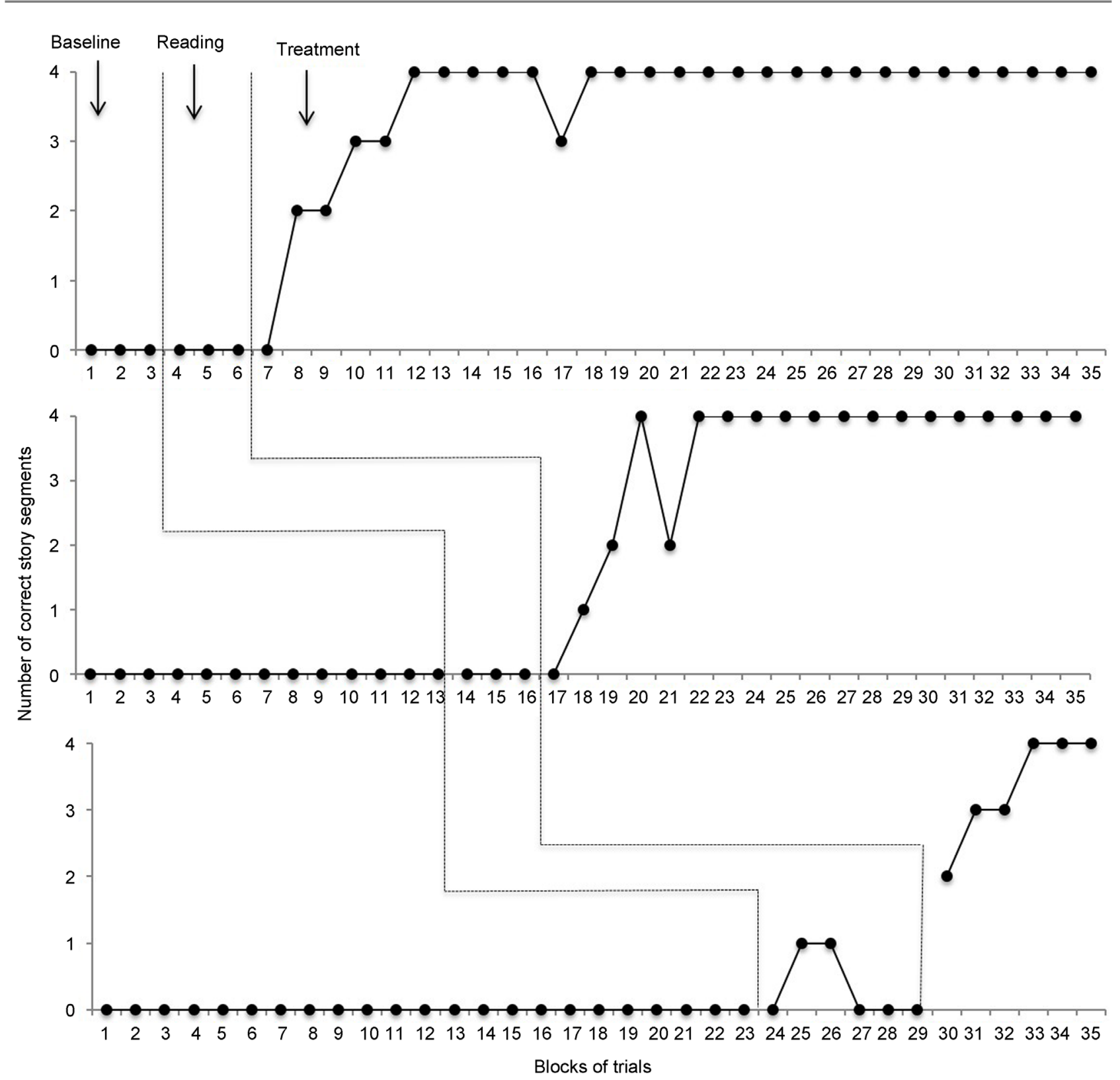

Figure 4. Number of correct story segments by P4 during baseline, reading and treatment condition. The upper, middle and lower graphs represent stories 1,2 and 3, respectively.

since they had some textual repertoire. Echoic prompts were administered as well, but only when a participant was not able to read a given segment and could be benefitted with echoic prompts. Nevertheless, as a limitation of the study, data on reading and vocal imitation, when necessary, were not taken and this should be considered for future research.

In Valentino et al. (2015) research, the authors suggested that the Naming Theory (Horne \& Lowe, 1996) could be considered as a way to conceptualize the successful outcome in their study. This might be considered for the current study as well. According to the Naming Theory, naming is defined as responding both as speaker and a listener to a given stimulus. During Valentino et al. (2015) research, the experimenter sometimes pointed to and read (tact) the textual sti- 
muli (words and phrases) and the participants could act as listeners by orienting to the stimuli. This should be considered for this research as well, although the experimenter read the textual stimuli only when a given participant was not able to read the story independently. During these interventions, the participants were socially reinforced both as speaker and listener. As on the previous research, the participants sometimes had the opportunity to observe the experimenter while reading out loud and pointing to the words. The children may have participated as a speaker by covertly or overtly echoing the stimuli. In the current study, since reading the scripts was allowed, correct reading/textual behavior was also socially reinforced and may have contributed to the establishment of the correct intraverbal storytelling behavior. Also, the authors pointed out that recalling a story read by another person is an example of delayed vocal imitation. It is possible that on their research and also the current one, the participants may covertly have echoed the stories or parts of them.

Without a doubt, behavioral training has been appointed as a solid path to be followed not only by children with autism, but also by their guardians and teachers. Data produced in the APRENDE laboratory at Federal University of Pará-UFPA (Pará, Brazil), by Ferreira (2015) and Ferreira, Silva and Barros (2016) and in the LAPITEA laboratory at Ceuma University (Maranhão, Brazil), by Matos (2016) have corroborated previous studies (Lafasakis \& Sturmey, 2007; Sarokoff \& Sturmey, 2004) regarding the efficiency and viability of ABA training when attending children with autism through caregivers.

It is important to remember that, on Valentino et al. (2015) research, changes on the procedures were necessary for two of the three children involved, since they engaged in repetitive responding across all conditions of the study. The addition of a visual prompt, a blank book resembling the one used during treatment, was necessary for these participants. However, such adaptations were not needed for the two autistic participants of the current study, even though one of them used to engage in echolalia during interventions applied on his therapy sessions out of the context of the current study.

The intraverbal behavior is a verbal operant present in many interactions among human beings in lots of situations. It is, for example, extremely important in the context of school. Activities that comprise this ability are such as reading comprehension and those explored on the current research. Frequently, children diagnosed with autism and other cases of developmental disabilities show a poor performance on these tasks and this draws the attention to the need of specialized treatments that may amend the deficits. The present study in part replicates the one conducted by Valentino et al. (2015) and may represent a suitable way of ameliorating some difficulties shown by autistic children in tasks that comprise the intraverbal ability.

The scientific literature shows promising results obtained with interventions based on $\mathrm{ABA}$ and this study was directed to evaluate the effectiveness of an intraverbal teaching procedure for children with autism and language delays. Impairment in intraverbal repertoire is critical for many children with autism. 
The data of the present research suggest that the exposure of these individuals to the programming contingencies during treatment can be effective, even without the backward chaining procedure, according to the findings of Valentino et al. (2015). As a result, it is hoped that the study may intensify changes and adaptations in the context of school for students with ASD and other cases, especially with regard to the preparation of educational professionals dealing with this type of student.

Due to the learning specificities of children with autism and the challenges related to psychoeducational strategies for behavioral and cognitive advancement of the student with ASD, it is imperative that schools base their practices and institutional policies on scientifically consistent investigations, considering the results of this and of other studies, like the literature review Stichter, Riley-Tillman and Jimerson (2016). It is important that information derived from scientific research is made available to assist educational professionals in addressing educational challenges in a safe, competent and effective manner.

\section{References}

Braam, S. J., \& Poling, A. (1983). Development of Intraverbal Behavior in Mentally Retarded Individuals through Transfer of Stimulus Control Procedures: Classification of Verbal Responses. Applied Research in Mental Retardation, 4, 279-302.

Brazil (2008). Política Nacional de Educação Especial na Perspectiva da Educação Inclusiva. Brasília: MEC/SEESP.

Brazil (2012). Política Nacional de Proteção dos Direitos das Pessoas com Transtorno do Espectro do Autismo. Brasília: MEC/SEESP.

Coon, J. T., \& Miguel, C. F. (2012). The Role of Increased Exposure to Transfer-ofStimulus Control Procedures on the Acquisition of Intraverbal Behavior. Journal of Applied Behavior Analysis, 45, 657-666.

Elsabbagh, M., Divan, G., Koh, Y. J., Kim, Y. S., Kauchali, S., Marcín, C., Montiel-Nava, C., Patel, V., Paula, C. S., Wang, C., Yasamy, M. T., \& Fombonne E. (2012). Global Prevalence of Autism and Other Pervasive Developmental Disorders. Autism Research, 5, 160-179. https://doi.org/10.1002/aur.239

Emmick, J. R., Cihon, T. M., \& Eshleman, J. W. (2010). The Effects of Textual Prompting and Reading Fluency on the Acquisition of Intraverbals. The Analysis of Verbal Behavior, 26, 31-39.

Ferreira, L. A. (2015). Ensino conceitual em ABA e Treino de Ensino por Tentativas Discretas para cuidadores de crianças com autismo. Dissertação de Mestrado, Programa de Pós-Graduação em Teoria e Pesquisa do Comportamento. UFPA. Belém-PA.

Ferreira, L. A., Silva, A. J. M., \& Barros, R. S. (2016). Ensino de aplicação de tentativas discretas a cuidadores de crianças diagnosticadas com autismo. Perspectivas em análise do comportamento, 7, 101-113. https://doi.org/10.18761/pac.2015.034

Finkel, A. S., \& Williams, R. L. (2001). A Comparison of Textual and Echoic Prompts on the Acquisition of Intraverbal Behavior in a Six-Year-Old Boy with Autism. The Analysis of Verbal Behavior, 18, 61-70.

Fleith, D. S. (2011). A Política Nacional de Educação Especial na Perspectiva da Educação Inclusiva: desafios para o Psicólogo Escolar. In C. M. Marinho-Araujo, \& R. S. L. Guzzo (Eds.), Psicologia escolar: Identificando e superando barreiras (pp. 33-46). Campinas: Alínea. 
Galvão, P. G., \& Beckman, M. V. R. (2016). A Educação Inclusiva no Contexto da Política Nacional da Educação Especial: Atuação e Compromisso da Psicologia Escolar. In D. C. Matos (Ed.), Análise do Comportamento Aplicada ao Desenvolvimento Atípico com Enfase em Autismo (pp. 199-226). Porto Velho: AICSA.

Garbacz, S. A., \& McIntyre, L. L. (2016). Conjoint Behavioral Consultation for Children with Autism Spectrum Disorder. School Psychology Quarterly, 31, 450-466. https://doi.org/10.1037/spq0000114

Goitein, P. C., \& Cia, F. (2011). Interações Familiares de Crianças com Necessidades Educacionais Especiais: Revisão da Literatura Nacional. Psicologia Escolar e Educacional, 15, 43-51. https://doi.org/10.1590/S1413-85572011000100005

Goldsmith, T. R., LeBlanc, L. A., \& Sautter, R. A. (2007). Teaching Intraverbal Behavior to Children with Autism. Research in Autism Spectrum Disorders, 1, 1-13.

Gomes, C. G. S., Silveira, A. D., \& Rates, A. C. (2016). Ensino de habilidades básicas para pessoas com autismo: manual para Intervenção Comportamental Intensiva. Curitiba: Appris.

Grannan, L., \& Rehfeldt, R. A. (2012). Emergent Intraverbal Responses Via Tact and Match-to-Sample Instruction. Journal of Applied Behavior Analysis, 45, 601-605. https://doi.org/10.1901/jaba.2012.45-601

Horne, P. J., \& Lowe, C. F. (1996). On the Origins of Naming and Other Symbolic Behavior. Journal of Experimental Analysis of Behavior, 65, 185-241. https://doi.org/10.1901/jeab.1996.65-185

Humphreys, T., Polick, A. S., Howk, L. L., Thaxton, J. R., \& Ivancic, A. P. (2013). An Evaluation of Repeating the Discriminative Stimulus When Using Least-to-Most Prompting to Teach Intraverbal Behavior to Children with Autism. Journal of Applied Behavior Analysis, 46, 534-538. https://doi.org/10.1002/jaba.43

Ingvarsson, E. T. (2011). Further Evaluation of Prompting Tactics for Establishing Intraverbal Responding in Children with Autism. The Analysis of Verbal Behavior, 27, 75-93.

Ingvarsson, E. T., \& Hollobaugh, T. (2011). A Comparison of Prompting Tactics to Establish Intraverbals in Children with Autism. Journal of Applied Behavior Analysis, 44, 659-664. https://doi.org/10.1901/jaba.2011.44-659

Kodak, T., Fuchtman, \& Paden, A. (2012). A Comparison of Intraverbal Training Procedures for Children with Autism. Journal of Applied Behavior Analysis, 45, 155-160. https://doi.org/10.1901/jaba.2012.45-155

Lafasakis, M., \& Sturmey, P. (2007). Training Parent Implementation of Discrete-Trial Teaching: Effects on Generalization of Parent Teaching and Child Correct Responding. Journal of Applied Behavior Analysis, 40, 685-689. https://doi.org/10.1901/jaba.2007.685-689

Lovaas, O. I. (1987). Behavioral Treatment and Normal Educational and Intellectual Functioning in Young Autistic Children. Journal of Consulting \& Clinical Psychology, 55, 3-9. https://doi.org/10.1037/0022-006X.55.1.3

Matos, D. C. (2016) Análise do comportamento aplicada ao desenvolvimento atípico com ênfase em autismo. Porto Velho: AICSA.

McEachin, J. J., Smith, T., \& Lovaas, O. I. (1993). Long-Term Outcome for Children with Autism Who Received Early Intensive Behavioral Treatment. American Journal on Mental Retardation, 97, 359-372.

Miguel, C. F., Petursdottir, A. I., \& Carr, J. E. (2005). The Effects of Multiple-Tact and Receptive-Discrimination Instruction on the Acquisition of Intraverbal Behavior. The Analysis of Verbal Behavior, 21, 27-41. 
Mitjáns-Martinez, A. M. (2009). Psicologia Escolar e Educacional: compromissos com a educação brasileira. Psicologia Escolar e Educacional, 13, 169-177. https://doi.org/10.1590/S1413-85572009000100020

Nunes, D. R. P., \& Santos, L. B. (2015). Mesclando Práticas em Comunicação Alternativa: Caso de uma Criança com Autismo. Psicologia Escolar e Educacional, 19, 59-69. https://doi.org/10.1590/2175-3539/2015/0191797

Partington, J. W., \& Bailey, J. S. (1993). Teaching Intraverbal Behavior to Preschool Children. The Analysis of Verbal Behavior, 11, 9-18.

Petursdottir, A. I., Carr, J. E., Lechago, S. A., \& Almason, S. M. (2008). An Evaluation of Intraverbal Instruction and Listener Instruction for Teaching Categorization Skills. Journal of Applied Behavior Analysis, 41, 53-68. https://doi.org/10.1901/jaba.2008.41-53

Petursdottir, A. I., Ólafsdóttir, \& Aradóttir, B. (2008). The Effects of Tact and Listener Training on the Emergence of Bidirectional Intraverbal Relations. Journal of Applied Behavior Analysis, 41, 411-415. https://doi.org/10.1901/jaba.2008.41-411

Polick, A. S., Carr, J. E., \& Hanney, N. M. (2012). A Comparison of General and Descriptive Praise in Teaching Intraverbal Behavior to Children with Autism. Journal of Applied Behavior Analysis, 45, 593-599.

https://doi.org/10.1901/jaba.2012.45-593

Sallows, G. O., \& Graupner, T. D. (2005). Intensive Behavioral Treatment for Children with Autism: Four-Year Outcome and Predictors. American Journal of Mental Retardation, 110, 417-428. https://doi.org/10.1352/0895-8017(2005)110[417:IBTFCW]2.0.CO;2

Sarokoff, R. A., \& Sturmey, P. (2004). The Effects of Behavioral Skills Training on Staff Implementation of Discrete-Trial Teaching. Journal of Applied Behavior Analysis, 37, 535-538. https://doi.org/10.1901/jaba.2004.37-535

Sautter, R. A., LeBlanc, L. A., Jay, A. A., Goldsmith, \& Carr, J. E. (2011). The Role of Problem Solving in Complex Intraverbal Repertoires. Journal of Applied Behavior Analysis, 44, 227-244. https://doi.org/10.1901/jaba.2011.44-227

Skinner, B. F. (1957). Verbal Behavior. New York, NY: Appleton-Century-Crofts. https://doi.org/10.1037/11256-000

Stichter, J. P., Riley-Tillman, C., \& Jimerson, S. R. (2016). Assessing, Understanding, and Supporting Students with Autism at School: Contemporary Science, Practice, and Policy. School Psychology Quarterly, 31, 443-449.

https://doi.org/10.1037/spq0000184

Sundberg, C. T., \& Sundberg, M. L. (1990). Comparing Topography-Based Verbal Behavior with Stimulus Selection-Based Verbal Behavior. The Analysis of Verbal Behavior, 8, 31-41.

Sundberg, M. L. (2008). The Verbal Behavior Milestones Assessment and Placement Program: The VB-MAPP(2nd ed.). Concord, CA: AVB Press.

Valentino, A. L., Shillingsburg, M. A., \& Call, N. A. (2012). Comparing the Effects of Echoic Prompts and Echoic Prompts plus Modeled Prompts on Intraverbal Behavior. Journal of Applied Behavior Analysis, 45, 431-435. https://doi.org/10.1901/jaba.2012.45-431

Vedora, J., \& Conant, E. (2015). A Comparison of Prompting Tactics for Teaching Intraverbals to Young Adults with Autismo. The Analysis of Verbal Behavior, 31, 267-276.

Vedora, J., \& Meunier, L. (2009). Teaching Intraverbal Behavior to Children with Autism: A Comparison of Textual and Echoic Prompts. The Analysis of Verbal Behavior, 25, 79-86. https://doi.org/10.1007/s40616-015-0030-6 
Submit or recommend next manuscript to SCIRP and we will provide best service for you:

Accepting pre-submission inquiries through Email, Facebook, LinkedIn, Twitter, etc. A wide selection of journals (inclusive of 9 subjects, more than 200 journals)

Providing 24-hour high-quality service

User-friendly online submission system

Fair and swift peer-review system

Efficient typesetting and proofreading procedure

Display of the result of downloads and visits, as well as the number of cited articles Maximum dissemination of your research work

Submit your manuscript at: http://papersubmission.scirp.org/

Or contact psych@scirp.org 